\title{
Treatment of Menopausal Symptoms in Family Medicine Settings following the Women's Health Initiative Findings
}

\author{
The Florida Behavioral Health Research Consortium; Mary Ann Burg, LCSW, PhD, \\ Kathryn Fraser, PhD, Serena Gui, PhD, Kathryn Grant, PhD, \\ Shae Graham Kosch, PhD, Barry Nierenberg, ABPP, PhD, Oliver Oyama, PhD, \\ Heidi Pomm, PhD, Kimberly Sibille, LMHC, Timothy Spruill, EdD, and \\ Virginia Swartz, DSW
}

Purpose: This study explores trends in treatment of menopausal symptoms and use of hormone replacement therapy (HRT) in family medicine settings subsequent to the release of the Women's Health Initiative (WHI) findings.

Methods: Anonymous self-administered questionnaires were distributed to family medicine residents and faculty from 8 participating family medicine residency programs in the state of Florida. The survey asked physicians how they typically treated common menopausal symptoms in otherwise healthy menopausal women, and how their practice patterns had changed since the release of the WHI findings. We analyzed survey responses from 62 faculty and 148 residents (66\% of eligible respondents).

Results: HRT is still prominent for treating irregular menses, vaginal dryness, vasomotor symptoms, and decreased libido. Faculty physicians were significantly more likely than residents to use HRT for menopausal symptoms. Female physicians were more likely than male physicians to say their treatment patterns had changed as a result of the WHI.

Conclusions: After weighing the evidence of potential risks of HRT from the WHI study, family medicine physicians altered and broadened their strategies for treating common menopausal symptoms. Although HRT remains a prominent treatment approach, there is now more physician-patient discussion of individual risks and benefits than occurred before the WHI's release of findings. ( $\mathrm{J}$ Am Board Fam Med 2006;19:122-31.)

There are diverse findings regarding the rates and progression of menopausal symptoms in women aged 45 years and older. There is evidence that up to $80 \%$ of women will experience some level of physical and/or psychological symptoms during perimenopause and menopause including vasomotor symptoms, vaginal dryness, sleep disturbances, changes in libido, mood changes, and fatigue. ${ }^{1,2} \mathrm{An}$

Submitted 26 April 2005; revised 14 June 2005; accepted 20 June 2005.

From the University of Florida, Gainesville, FL (MAB, KG, SGK); Halifax Medical Center, Daytona Beach, FL (KF); Florida Hospital, Orlando (SG, TS); University of Miami School of Medicine, Miami, FL (BN); Morton Plant Mease/University of South Florida, Clearwater, FL (OO); St. Vincent's Medical Center, Jacksonville (HP); Bayfront Medical Center, St. Petersburg, FL (KS); University of Florida-Shands Jacksonville (VS).

Conflict of interest: none declared.

Corresponding author: Mary Ann Burg, LCSW, PhD, Women's Health Research Center, Box 100171, University of Florida, Gainesville, FL 32610-0171 (E-mail: burg@ vpha.ufl.edu).
Australian study found that between early and late perimenopause, hot flushes increased by $27 \%$, night sweats by $17 \%$, vaginal dryness by $17 \%$, whereas sleep disturbance progressed at a more gradual rate of $6 \% .^{3}$

Until 2002, physicians recommended hormone replacement therapy (HRT) as a first line treatment of common menopausal symptoms and as a prudent approach for the primary prevention of coronary heart disease (CHD) in menopausal women. ${ }^{4-5} \mathrm{Be}-$ tween 1995 and 2002, HRT prescriptions increased from 58 million to 91 million annually. The percentage of patient visits for HRT increased from $5 \%$ to $28 \%$, and $90 \%$ of physicians reported prescribing HRT primarily for treatment of menopausal symptoms. ${ }^{6}$

The Women's Health Initiative (WHI) was a multi-site randomized clinical trial designed to assess the effects of conjugated equine estrogen alone (for women with prior hysterectomy) and estrogen 
plus progestin (for women with intact uteri) on CHD incidence, and to examine the overall risks and benefits of HRT for rates of invasive breast cancer, stroke, pulmonary embolism, endometrial and colorectal cancer, and hip fracture in postmenopausal women 50 to 79 years old. ${ }^{7}$ Between 1993 and 1998, this 40-site randomized trial enrolled 16,608 women in the study arm comparing combined estrogen/progestin (Prempro) to placebo. This study arm was halted in May 2002 after investigators found that the associated health risks of the combination hormone therapy outweighed the benefits. The preliminary data showed a $26 \%$ increase in relative breast cancer risk and increased relative risk in CHD events. ${ }^{8}$ Guidelines for the use of HRT were quickly amended: the American Heart Association recommended against initiating combined estrogen and progestin for secondary prevention of CHD, and the US Preventive Services Task Force recommended against women taking HRT solely for the purpose of preventing chronic conditions. ${ }^{9-11}$ The early discontinuation of the WHI estrogen/progestin clinical trial created an intense media and public reaction to the reports of potential harm from HRT. There was a rapid decline in prescriptions for HRT, most specifically Prempro, the HRT used in the WHI. Between the second quarter of 2002 and the last quarter of 2004, prescriptions for Prempro dropped by $80 \% .^{6,12}$ Subsequently in March 2004, the WHI's estrogen-alone arm of the trial was also terminated early, when analyses of the data showed an increased risk of stroke and no overall benefit for CHD. ${ }^{13}$

Other than the evidence of declining prescribing of HRT in the years following the WHI findings, there is little evidence of how physicians now manage menopause symptoms subsequent to the WHI findings. Are physicians now suggesting other treatment approaches such as lifestyle changes, psychotropic medications or complementary therapies for symptom management? Are physicians restricting HRT for otherwise healthy women, or are there some physicians, eg, those who have been practicing for many years, still recommending HRT to most of their symptomatic patients? We undertook this study to explore trends in treatment practices of family medicine physicians in the 2 years subsequent to the release of the WHI findings.

\section{Methods}

\section{Study Design and Population}

The University of Florida Institutional Review Board approved this study protocol in 2004. The data presented are from a cross-sectional survey of interns, residents, and faculty of the 8 participating family medicine residency programs in Florida. The participating programs are those whose behavioral medicine/science faculty or staff participated in the Florida Behavioral Health Research Consortium (FBHRC). All the participating programs have family medicine centers where faculty and residents see patients in a community setting.

Eligible respondents were all Family Medicine interns, residents, and faculty in these 8 programs. We excluded surveys completed by non-physician clinicians (eg, physician assistants and nurse practitioners) and physicians who were in specialties other than family medicine because they were such a small proportion of the total sample ( $\mathrm{n}=5$ and $\mathrm{n}=8$, respectively). Overall there were 229 eligible residents and 90 eligible program faculty in family medicine.

\section{Survey Administration}

The FBHRC members distributed the surveys at their program sites between the months of June 2004 and August 2004. Several methods were used for survey distribution, including handing surveys out at residency program meetings, putting them in resident and faculty mail boxes, and giving them directly to eligible respondents. To maintain anonymity, the FBHRC members were asked to instruct respondents to complete and return the surveys with no identifiers on the survey. The FBHRC members then mailed the completed surveys to the residency program site responsible for final collection and entry of the data.

\section{Survey Content}

The FBHRC met several times over the course of a year to develop and to refine the survey questions. The survey instrument was also reviewed and pretested by the program directors at each of the participating residency programs, and their suggestions for changes were incorporated into the final survey instrument.

The final instrument was a 2-page self-administered questionnaire that took approximately $5 \mathrm{~min}$ utes to complete. The survey elicited demographic 
information including gender, specialty, and year residency training was/would be completed. To evaluate the volume of practice respondents had with menopausal patients, we also asked respondents to estimate the approximate number of women patients aged 45 to 65 they saw in their practice in an average week.

For this study, we analyzed responses to 3 sets of survey items. First, we provided a list of 9 common menopausal symptoms (vaginal dryness, vasomotor symptoms, sleep disturbance, decreased libido, emotional lability, anxiety, depression, irregular menses, and fatigue). Respondents were asked to indicate the approximate proportion of female patients aged 45 to 65 for whom each of these symptoms was present. Response categories were $0 \%$ to $25 \%, 26 \%$ to $50 \%, 51 \%$ to $75 \%$, and $76 \%$ to $100 \%$. Next, we asked them to refer to a list of 9 common menopausal symptoms and to indicate which modes of treatment (wait and see, hormone therapy, psychotropic medications, lifestyle changes, alternative therapies, or other) they typically recommended to female patients aged 45 to 65 who reported these symptoms but who were in otherwise good overall health. They were instructed to check as many of the modes of treatment that applied. They were also asked to what extent their practice patterns had changed as a result of the WHI study results published so far. Response categories were "a great deal," "somewhat," "not much at all," and "unsure." If their practice patterns had changed, they were asked to briefly explain the changes in an open-ended format.

\section{Analysis}

Based on responses to the year residency was completed, we created a new variable indicating if the respondent was a resident or a faculty member at the time of the survey (ie, those who completed residency in 2003 or earlier were coded as faculty; those who were completing residency in 2004 or later were coded residents). Responses to the item that asked respondents to estimate the approximate number of women patients aged 45 to 65 that they saw in their practice in an average week were recoded into a categorical variable for the bivariate comparisons in the analysis (ie, " 1 to 10 ," "11 to 20 ," "21 or more"). Responses to the item asking respondents about the proportion of their female patients who presented with any of the 9 listed menopausal symptoms were recoded into a bivariate response variable where $1=$ the majority of patients and $0=$ less than half of patients. Descriptive statistics were used to examine the distribution of responses to all the survey items: $\chi^{2}$ significance tests were used to examine bivariate associations in the data; $t$ tests were used to examine significant differences in the means of continuous variables in the data. Responses to the open-ended question about how respondent's practices had changed in response to the WHI findings were coded into thematic categories and reported as such in the analysis.

\section{Results}

\section{Respondent Characteristics}

Out of the 319 eligible respondents, 210 returned completed surveys for an overall response rate of $66 \%$. Almost three quarters of the survey respondents were family medicine residents and the remainder were family medicine residency program faculty (Table 1). Specific response rates for faculty and residents were 69\% (62/90) and 65\% (148/ $229)$, respectively. The majority of respondents were women. The mean number of women patients aged 45 to 65 seen by all respondents in an average week in the total sample was $14.9(\mathrm{SD}=13.6)$; residents reported a mean of $13.7(\mathrm{SD}=11.2)$ female patients aged 45 to 65 per week, and faculty reported a mean of $16.8(\mathrm{SD}=14.7)$ each week. The difference between the mean numbers of women seen by residents versus faculty respondents was not significant.

Table 1. Characteristics of Physician Respondents to Survey

\begin{tabular}{lrc}
\hline & N & Percentage \\
\hline Residents & 148 & 72.5 \\
Faculty & 62 & 27.5 \\
Female & 120 & 57.7 \\
Male & 88 & 42.3 \\
Female Residents & 80 & 54.1 \\
Male Residents & 68 & 45.9 \\
Female Faculty & 35 & 62.5 \\
Male Faculty & 21 & 37.5 \\
Average number of women patients & & \\
$\quad$ aged 45 to 65 seen each week: & & \\
1 to 10 & 108 & 53.7 \\
11 to 20 & 57 & 28.4 \\
21 or more & 36 & 17.9 \\
\hline
\end{tabular}


Frequency of Menopause Symptoms Seen in Patients

Respondents were asked to indicate the frequency with which they saw each of the 9 listed menopausal symptoms in their patients. Approximately one third of the physicians saw fatigue, vasomotor symptoms, irregular menses, and emotional lability in the majority of female patients aged 45 to 65 (Table 2). About one fourth of the physicians said sleep disturbances, depression, and anxiety were common in the majority of female patients. There were no significant associations between training status (ie, residents versus faculty) or respondent gender and responses to any of these items. There was a positive relationship between the number of female patients aged 45 to 65 seen in an average week and patient reports of fatigue: $31 \%$ of respondents who saw only 1 to 10 female patients per week said that half or more of their patients reported fatigue, whereas $54 \%$ of respondents who saw 21 or more female patients per week said that half or more of their patients reported fatigue $(P=$ $.035)$.

\section{Respondent Differences in Treatment Modalities Recommended for Specific Common Menopausal Symptoms}

Figures 1 to 9 show the treatment modalities recommended for each of the common menopausal symptoms. Respondents were instructed to check all the treatment recommendations they used for each menopausal symptom in female patients age 45 to 65 who were in otherwise good health. The majority of respondents recommended hormone therapy for vaginal dryness $(69 \%)$, and very few recommended any other types of therapeutic ap-

Table 2. Percentage of Physicians Who Say That Common Menopausal Symptoms Are Present in Majority of Women Patients Aged 45 to 65:

\begin{tabular}{lc}
\hline $\begin{array}{l}\text { Symptoms Reported in } \\
\text { Majority of Patients }\end{array}$ & $\begin{array}{c}\text { Percentage } \\
\text { of Physicians }\end{array}$ \\
\hline Fatigue & 40.1 \\
Vasomotor symptoms & 38.9 \\
Irregular menses & 36.9 \\
Emotional lability & 35 \\
Sleep disturbance & 25.4 \\
Depression & 24 \\
Anxiety & 23.7 \\
Decreased libido & 17.9 \\
Vaginal dryness & 13.6 \\
\hline
\end{tabular}

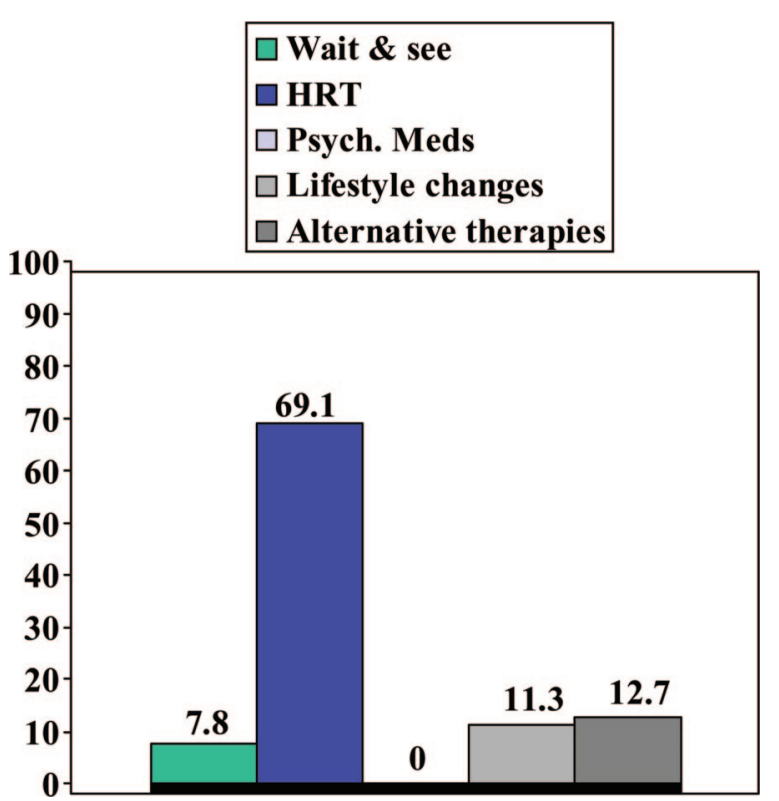

Figure 1. Percentage of Physicians Using Specific Treatment Modalities for Vaginal Dryness.

proaches for this symptom. Of those recommending hormone therapy for vaginal dryness, $10.3 \%$ wrote in topical hormones under "other therapies," whereas $29.9 \%$ of those who did not recommend hormone therapy for vaginal dryness wrote in topical hormones. Treatment recommendations for vasomotor symptoms were diverse with half of the respondents recommending hormone therapy,

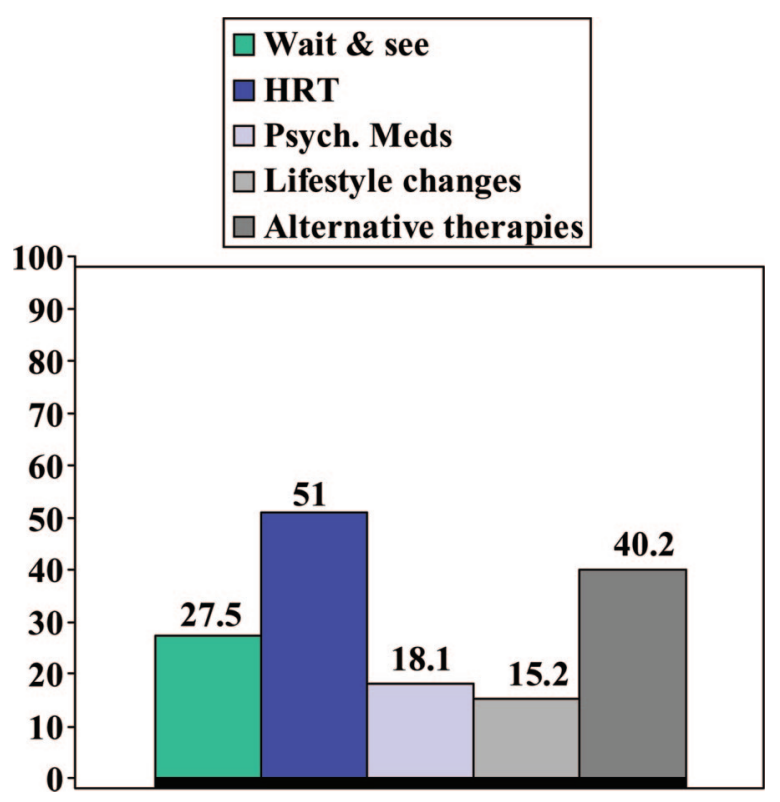

Figure 2. Percentage of Physicians Using Specific Treatment Modalities for Vasomotor Symptoms. 


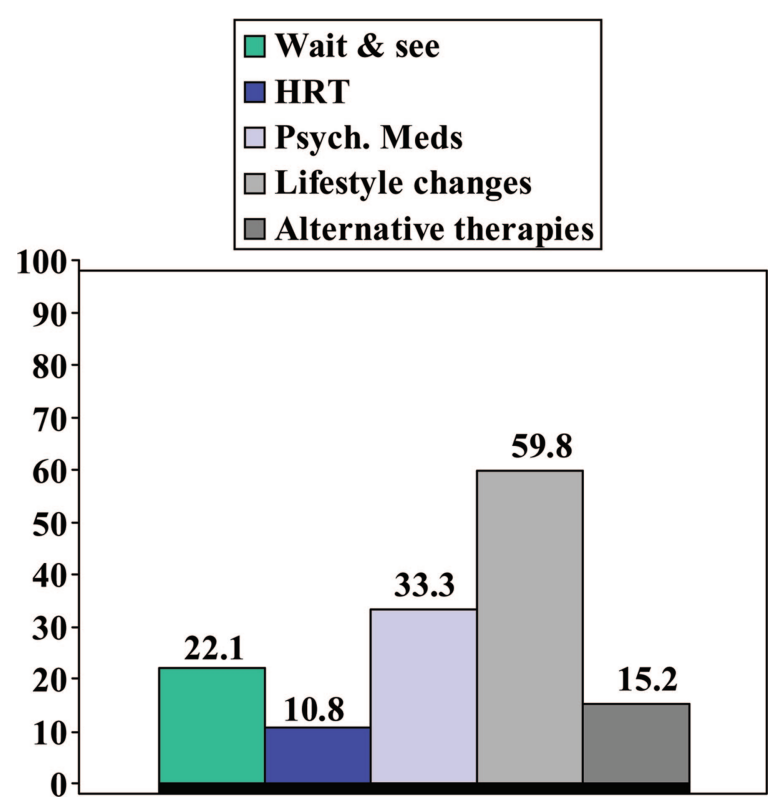

Figure 3. Percentage of Physicians Using Specific Treatment Modalities for Sleep Disturbance.

$40 \%$ recommending alternative therapies, 28\% recommending "wait and see," $18 \%$ recommending psychotropic medications, and 15\% recommending lifestyle changes. The majority of respondents recommended lifestyle changes for sleep disturbance, approximately one third recommended psychotropic medications, and approxi-

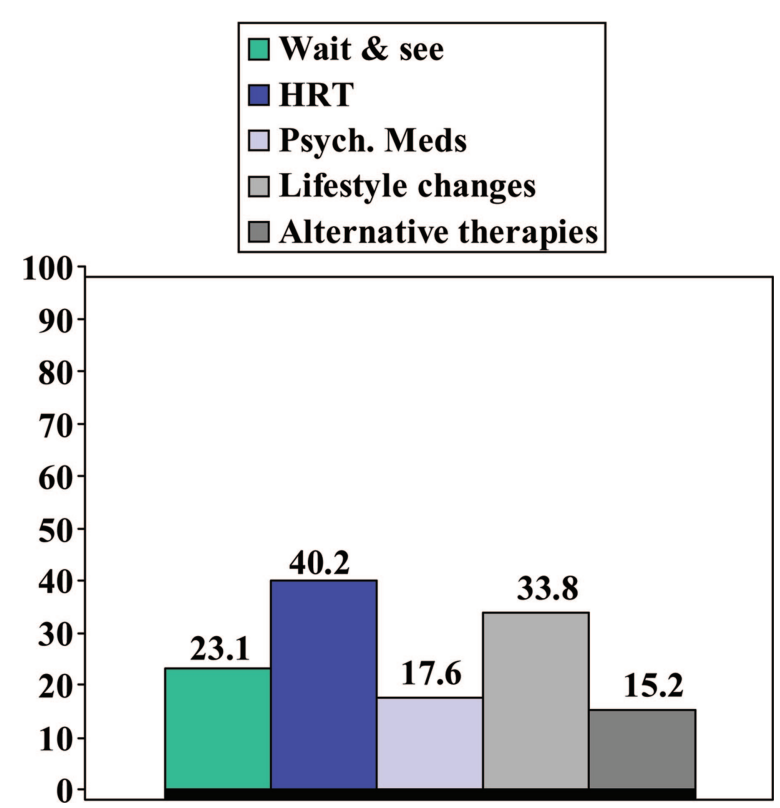

Figure 4. Percentage of Physicians Using Specific Treatment Modalities for Decreased Libido.

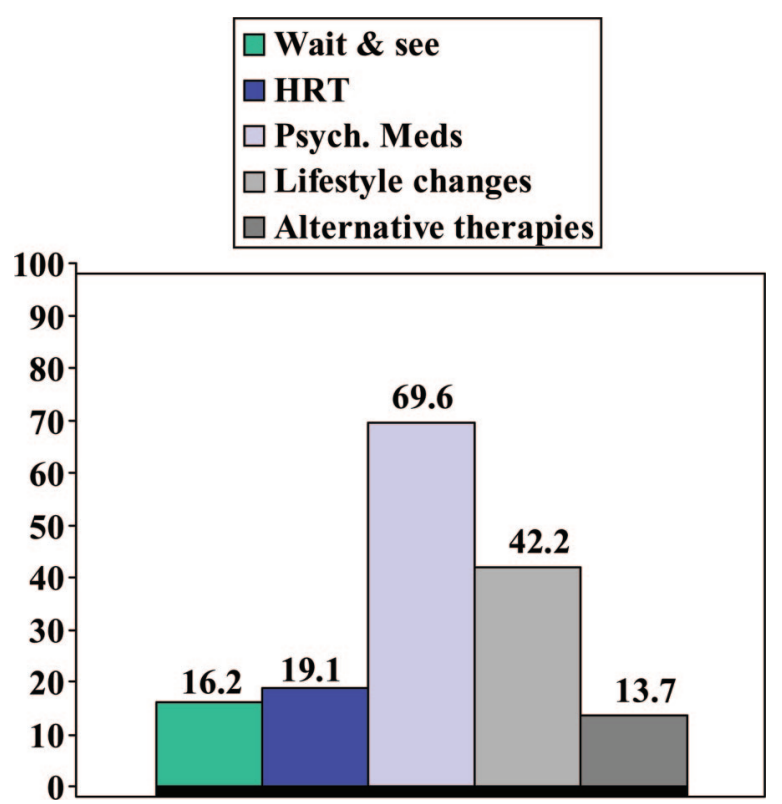

Figure 5. Percentage of Physicians Using Specific Treatment Modalities for Emotional Lability.

mately one fifth recommended "wait and see." Decreased libido was another symptom that generated diverse therapeutic responses in this sample, with HRT being the most frequent response. Emotional lability, depression, and anxiety were all treated primarily with psychotropic medications and lifestyle changes. Respondents were almost equally

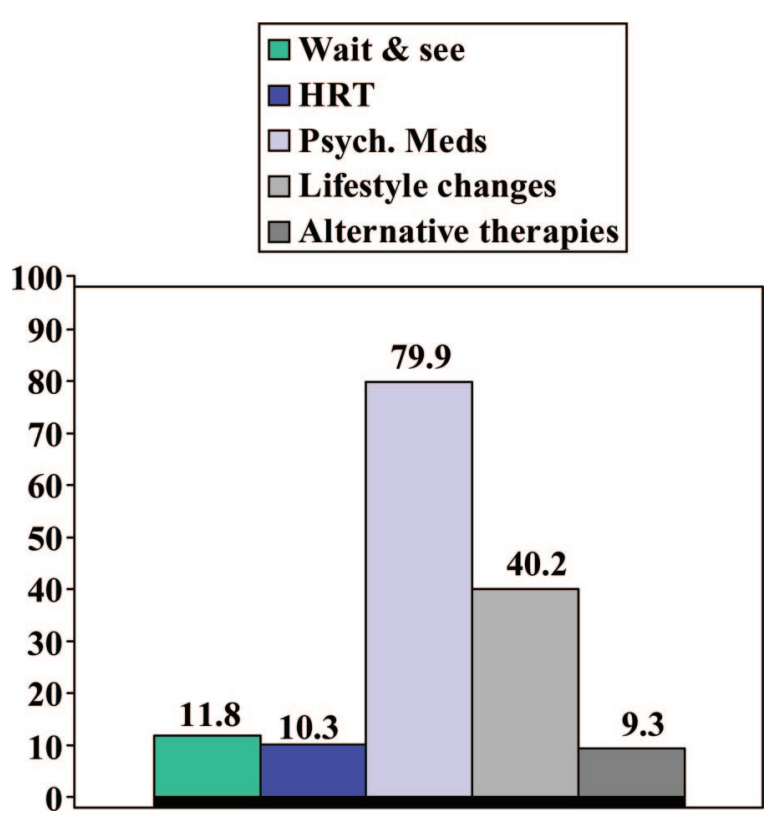

Figure 6. Percentage of Physicians Using Specific Treatment Modalities for Anxiety. 


\section{$\square$ Wait \& see \\ $\square$ HRT \\ $\square$ Psych. Meds \\ $\square$ Lifestyle changes \\ $\square$ Alternative therapies}

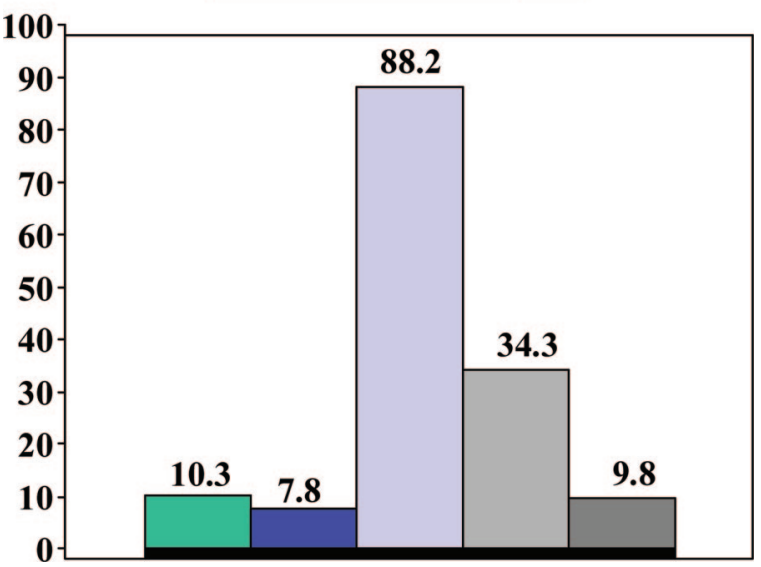

Figure 7. Percentage of Physicians Using Specific Treatment Modalities for Depression.

likely to recommend "wait and see" and hormonal treatment for irregular menses. The majority of respondents recommended lifestyle changes, one fourth recommended "wait and see," and one fifth recommended alternative therapies for fatigue.

Table 3 summarizes the previous 9 charts by displaying the relative frequency of treatment rec-

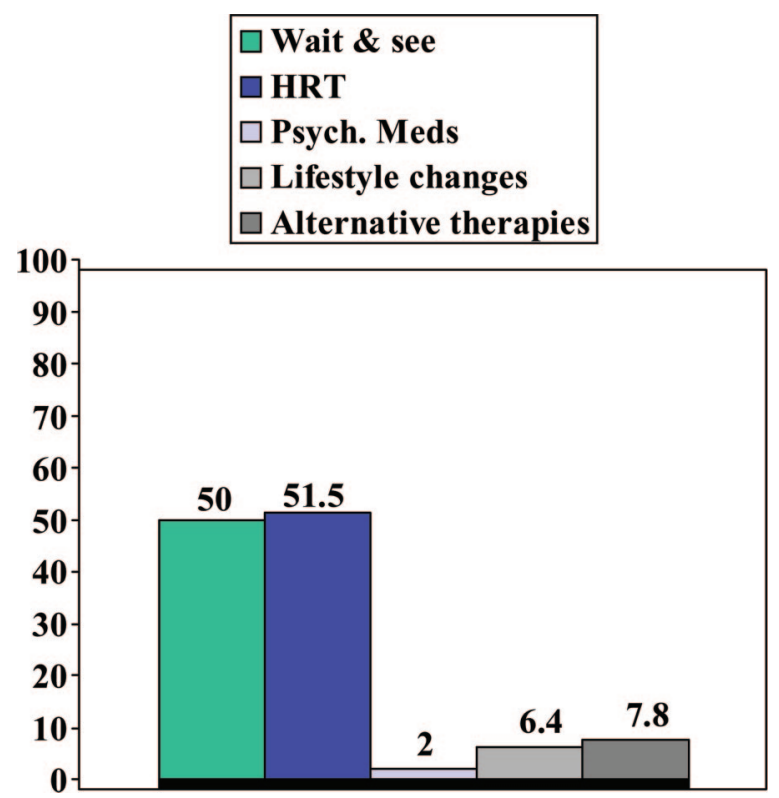

Figure 8. Percentage of Physicians Using Specific Treatment Modalities for Irregular Menses.
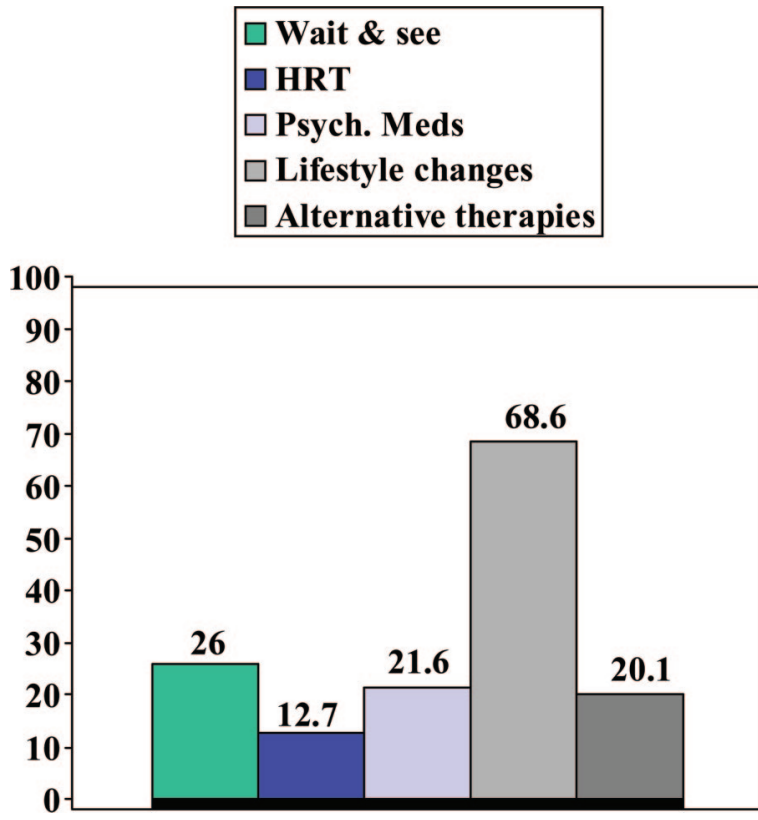

Figure 9. Percentage of Physicians Using Specific Treatment Modalities for Fatigue.

ommendations in a hierarchy table from high to low frequency for each of the 9 menopausal symptoms. The table shows that hormone treatment was the primary mode of treatment recommended to women patients who reported irregular menses, vaginal dryness, vasomotor symptoms, and decreased libido. There were no obvious trends in the use of other therapeutic modalities for addressing menopausal symptoms. Complementary and alternative medicine (CAM) therapies were recommended most often for vaginal dryness and vasomotor symptoms.

\section{Analysis of Hormonal Therapy Recommendations}

Table 4 shows data comparing the percentage of residents versus faculty who reported recommending hormone treatment for the listed menopausal symptoms. Faculty respondents were significantly more likely than residents to report recommending hormone therapy for the following symptoms: vasomotor symptoms, sleep disturbance, decreased libido, emotional lability, anxiety, irregular menses, and fatigue. There were no significant differences between faculty and residents in recommending hormone therapy for vaginal dryness and depression.

We also looked specifically at faculty respondents and examined the associations between time since completion of residency training and use of 
Table 3. Hierarchy of Treatment Recommendations For Common Menopausal Symptoms (Percentages)

\begin{tabular}{|c|c|c|c|c|c|c|c|}
\hline & $\begin{array}{l}\text { Irregular } \\
\text { Menses }\end{array}$ & $\begin{array}{l}\text { Vaginal } \\
\text { Dryness }\end{array}$ & $\begin{array}{l}\text { Vasomotor } \\
\text { Symptoms }\end{array}$ & $\begin{array}{c}\text { Sleep } \\
\text { Disturbance }\end{array}$ & $\begin{array}{l}\text { Decreased } \\
\text { Libido }\end{array}$ & $\begin{array}{l}\text { Emotional } \\
\text { Lability }\end{array}$ & Fatigue \\
\hline \multirow[t]{4}{*}{ Higher } & HRT (50.9) & HRT (68.4) & HRT (50.9) & $\begin{array}{l}\text { Lifestyle } \\
\text { changes } \\
(58.5)\end{array}$ & HRT (39.2) & $\begin{array}{l}\text { Psych meds } \\
\text { (68.4) }\end{array}$ & $\begin{array}{l}\text { Lifestyle } \\
\text { changes } \\
(67.5)\end{array}$ \\
\hline & $\begin{array}{l}\text { Wait and see } \\
\quad(50)\end{array}$ & CAM (12.7) & CAM (39.6) & $\begin{array}{l}\text { Psych meds } \\
\text { (33) }\end{array}$ & $\begin{array}{l}\text { Lifestyle } \\
\text { changes } \\
(33.5)\end{array}$ & $\begin{array}{l}\text { Lifestyle } \\
\quad \text { changes (41) }\end{array}$ & $\begin{array}{l}\text { Wait and see } \\
\quad(25.9)\end{array}$ \\
\hline & CAM (8) & $\begin{array}{l}\text { Lifestyle } \\
\text { changes } \\
(11.3)\end{array}$ & $\begin{array}{l}\text { Wait and see } \\
\text { (27.4) }\end{array}$ & $\begin{array}{l}\text { Wait and see } \\
(22.2)\end{array}$ & $\begin{array}{l}\text { Wait and see } \\
\quad(24.1)\end{array}$ & HRT (18.4) & $\begin{array}{l}\text { Psych meds } \\
(20.8)\end{array}$ \\
\hline & $\begin{array}{l}\text { Lifestyle } \\
\quad \text { changes (6.1) }\end{array}$ & $\begin{array}{l}\text { Wait and see } \\
(8.5)\end{array}$ & $\begin{array}{l}\text { Psych. Meds } \\
\quad(17.5)\end{array}$ & CAM (15.6) & $\begin{array}{l}\text { Psych meds } \\
(17.5)\end{array}$ & $\begin{array}{l}\text { Wait and see } \\
\quad(16.5)\end{array}$ & CAM (19.8) \\
\hline Lower & $\begin{array}{l}\text { Psych.meds } \\
\text { (1.9) }\end{array}$ & $\begin{array}{l}\text { Psych.meds } \\
(0.5)\end{array}$ & $\begin{array}{l}\text { Lifestyle } \\
\text { changes } \\
(14.6)\end{array}$ & HRT (10.4) & CAM (15.1) & CAM (14.2) & HRT (13.2) \\
\hline
\end{tabular}

HRT, hormone replacement therapy; CAM, complementary and alternative medicine.

HRT for menopausal symptoms. There was a trend for faculty who had completed their residency training 10 years or more before the WHI results were published (ie, faculty who completed training in 1993 or earlier) to report recommending HRT for most menopausal symptoms (anxiety, depression, irregular menses, fatigue, vaginal dryness, vasomotor symptoms, and decreased libido) compared with faculty who completed training more recently, but none of the associations attained significance because of small sample sizes.

\section{Change in Treatment Patterns As a Result of WHI}

Overall, the majority of respondents reported that their practice patterns had changed as a result of the findings from the WHI study (Table 5). Specifically, $86 \%$ of the female faculty and $72 \%$ of the male faculty reported changing their practice patterns. Reports of changed practice were more frequent among respondents with higher volumes of female patients in an average week. Responses to the open-ended question to briefly explain changes in practice patterns fell into 8 general categories. In the order of frequency those categories are: (1) their use of HRT had been reduced; (2) they use it only for symptom relief and not preventive purposes; (3) they prescribe HRT for only brief periods, eg, 2 to 5 years; (4) they don't recommend it at all or rarely recommend it; (5) they engage in more discussion with patients about the risks and benefits of HRT and seek informed consent; (6) they suggest complementary and alternative therapy treatment approaches more often; and, (7) they report continuing confusion about the WHI results and how those findings should influence practice (Table 6).

\section{Discussion}

Until the year 2002, HRT was a standard approach in the treatment of common symptoms of menopause, and it was believed to provide some protection against heart disease and osteoporosis. New evidence of the potential risks of HRT from the WHI and several other large clinical trials generated prolific media coverage of the issue and at least a temporary decline in use of HRT by female patients. ${ }^{6,14-16}$

Table 4. Percentage Who Recommend Hormone Therapy for Menopausal Symptoms: Comparison of Residents to Faculty

\begin{tabular}{lccccccrrr}
\hline & \multicolumn{4}{c}{ Percentage Who Recommend Hormone Therapy For Specific Symptoms } \\
\cline { 2 - 9 } & $\begin{array}{l}\text { Vaginal } \\
\text { Dryness }\end{array}$ & $\begin{array}{c}\text { Vasomotor } \\
\text { Symptoms }\end{array}$ & $\begin{array}{c}\text { Sleep } \\
\text { Disturbance }\end{array}$ & $\begin{array}{c}\text { Decreased } \\
\text { Libido }\end{array}$ & $\begin{array}{c}\text { Emotional } \\
\text { Lability }\end{array}$ & Anxiety & Depression & $\begin{array}{c}\text { Irregular } \\
\text { Menses }\end{array}$ & Fatigue \\
\hline Residents & 68.9 & 41.2 & 6.1 & 35.1 & 12.8 & 7.4 & 6.1 & 45.9 & 8.9 \\
Faculty & 69.6 & 76.8 & 23.2 & 53.6 & 35.7 & 17.9 & 12.5 & 66.1 & 23.2 \\
$P$ value & NS & .001 & .001 & .025 & .001 & .001 & NS & .012 & .009 \\
\hline
\end{tabular}


Table 5. Percentage of Respondents Who Changed Practice Patterns after Women's Health Initiative Study Findings Were Published: by Gender, Training Status, and Average Number of Women Aged 45 to 65 Seen Each Week

$\begin{array}{ccc}\text { Not } & P \\ \text { Changed } & \text { changed } & \text { Value }\end{array}$

\begin{tabular}{lrrr}
$\begin{array}{l}\text { Total sample } \\
\text { Gender }\end{array}$ & & & \\
$\quad$ Female & 85.8 & 14.2 & $.014^{* *}$ \\
$\quad$ Male & 71.6 & 28.4 & \\
Training status & & & \\
$\quad$ Resident & 75.2 & 24.8 & $.005^{*}$ \\
$\quad$ Faculty & 92.7 & 7.3 & \\
Average number of female patients & & & \\
$\quad$ aged 45 to 65 seen each week & & & \\
1 to 10 & 75.2 & 24.8 & $.018^{* *}$ \\
11 to 20 & 80.7 & 19.3 & \\
21 or more & 97.1 & 2.9 & \\
\hline
\end{tabular}

${ }^{*} P<.05$.

${ }^{* *} P<.001$.

Our survey demonstrated that the WHI had significant impact on physician practice. Female residents and female faculty were more likely to report having changed their practice as a result of the WHI. The majority of family medicine faculty still recommended HRT as a treatment approach for the most common physical symptoms of menopause, but interns and residents were not as likely

Table 6. Common Answers to the Question, 'How Has Your Prescribing of Hormone Replacement Therapy (HRT) Changed Since Women's Health Initiative (WHI)?'

\footnotetext{
"I don't use HRT as preventive therapy. Still use as treatmen for acute symptoms after risks/benefits explained. Try to get people off it in 2 years or less. Use as a treatment rather than prevention or global measure"

"I prescribe HRT and ERT significantly less, taper it more quickly, and seek certain alternatives (specifically topical estrogen and Effexor) much more."

"Not confident about prescribing HRT anymore and only given for postmenopausal symptoms refractory to other treatment modalities. Confused about what emphasis to put on past research."

"The results were overblown. The absolute risks were not as staggering as the relative risks reported. For me, it triggers a discussion with the patient."

"I would like to know more about natural options. I would like to see more of this in residency training."

"I really don't like HRT and would not recommend it to any patients. I think things like soy and really more behavioral psychology approaches may be more helpful."
}

to recommend it. HRT was used less for preventive reasons, recommended mostly only for symptom relief, and was being prescribed only for brief periods, eg, 2 to 5 years, rather than indefinitely.

HRT was still the primary mode of treatment recommended to women patients who reported irregular menses, vaginal dryness, vasomotor symptoms, and decreased libido, but it was not commonly recommended for other menopausal symptoms. In this survey, treatment approaches for the other menopausal symptoms defied categorization. From the comments section of the survey, it seems that family medicine physicians are possibly more likely now to suggest CAM approaches for menopausal symptom management than they were before the release of the WHI findings. CAM was mentioned second only to HRT as a common treatment recommendation for both vasomotor symptoms and vaginal dryness. Remifemin (black cohosh), is an example of an alternative approach to menopausal symptom management. Remifemin has been shown through randomized clinical trials to be more effective than placebo in the treatment of hot flushes (two 20-mg tablets twice daily), and it has been recommended by the German Commission $\mathrm{E}$ Guidelines for the treatment of dysmenorrhea. ${ }^{17}$ Foods containing phytoestrogens have also demonstrated potential benefits for symptom relief, particularly hot flashes. ${ }^{18}$ For certain menopausal symptoms, eg, sleep disturbance, fatigue, decreased libido, and emotional lability, physicians generally advise patients to consider lifestyle changes for symptom relief. Although there is some limited evidence that supports using relaxation therapy to reduce vasomotor symptoms, future studies are needed to more clearly define the effects of other behavioral therapies and lifestyle changes on menopausal symptoms. ${ }^{19,20}$

It is evident from this survey of family medicine physicians that there is still some uncertainty about best practices to address menopausal symptoms, because of the lack of standardization of practice recommendations. There is also evidence that some ambiguity persists about which patients are candidates for HRT. ${ }^{21}$ A limitation of our survey is that it used as a point of reference for responses about HRT "menopausal patients in otherwise good health." This point of reference limits us in making any specific comments about some of the specific risks the physician respondents take into account in HRT treatment decisions, such as fam- 
ily history of coronary artery disease or breast cancer.

The conclusions of the recent National Institutes of Health consensus panel on "Management of Menopause-related Symptoms" added almost no specificity in regards to best practices in this area. ${ }^{22}$ The panel acknowledged that although HRT was still the most effective therapy for menopausal symptoms, it was important to consider the defined risks of HRT in deciding whether to recommend it as a therapy for menopausal women. The only specific guideline that emerged from the consensus panel was the following: "decision making for women regarding treatment for menopausal symptoms requires personal knowledge and balancing of these risks."

A clear and consistent finding of this study was that family medicine physicians report spending more time discussing the risks and benefits of HRT with their patients since the WHI findings were released. This is a valuable outcome of the WHI regardless of the clinical uncertainty that still surrounds the topic. Further studies regarding the nature of these discussions in combination with patients' interpretations of the information presented by the WHI may provide data that will be useful to family medicine physicians in their decision making and treatment of menopausal symptoms.

We thank the Residency Program Directors at each participating study site for comments on the survey and the manuscript: Bruce Flareau, MD (Morton Plant Mease/University of South Florida); Kristen Gray, MD (Florida Hospital); Karen Hall, MD (University of Florida); David McInnes, MD (St. Vincent's Medical Center); David Parrish, MS, MD (Bayfront Medical Center); Ed Prevatte, MD (Halifax Medical Center); Penny Tenzer, MD (University of Miami School of Medicine); and Anna M. Wright, MD (University of Florida, Jacksonville).

\section{References}

1. Cheung AM, Chaudry R, Kapral M, Jackvicius C, Robinson G. Perimenopausal and postmenopausal health. BMC Women's Health 2004;4(Suppl 1):S23.

2. Gracia CR, Freeman EW. Acute consequences of the menopausal transition: the rise of common menopausal symptoms. Endocrinol Metab Clin North Am 2004;33:675-89.

3. Dennerstein L, Duddley EC, Hopper JL, Guthrie JR, Burger HG. A prospective population-based study of menopausal symptoms. Obstet Gynecol 2000;96:351-8.

4. Cutson TM, Meuleman E. Managing menopause. Am Fam Physician 2000;61:1391-400.
5. Gorsky RD, Koplan JP, Peterson HB, Thacker SB. Relative risks and benefits of long-term estrogen replacement therapy: a decision analysis. Obstet Gynecol 1994;83:161-6.

6. Hersh AL, Stefanick ML, Stafford RS. National use of postmenopausal hormone therapy. JAMA 2004; 291:47-53.

7. The Women's Health Initiative Study Group. Design of the Women's Health Initiative clinical trial and observational study. Control Clin Trials 1998; 19:61-109.

8. Writing Group for the Women's Health Initiative Investigators. Risks and benefits of estrogen plus progestin in healthy postmenopausal women: Principal results from the Women's Health Initiative Randomized Control Trial. JAMA 2002;288:321-33.

9. Mosca L, Collins P, Herrrington DM, et al. Hormone replacement therapy and cardiovascular disease: a statement for healthcare professionals from the American Heart Association. Circulation 2001; 104:499-503.

10. Humphrey LL, Chan BKS, Sox HC. Postmenopausal hormone replacement therapy and the primary prevention of cardiovascular disease. Ann Intern Med 2002;137:273-84.

11. Majumdar SR, Almasi EA, Stafford RS. Promotion and prescribing of hormone therapy after report of harm by the Women's Health Initiative. JAMA 2004;292:1983-8.

12. The Women's Health Initiative Steering Committee. Effects of conjugated equine estrogen in postmenopausal women with hysterectomy. JAMA 2004; 291:1701-12.

13. Barber CA, Margolis K, Luepker RV, Arnett DK. The impact of the Women's Health Initiative on discontinuation of postmenopausal hormone therapy: the Minnesota Heart Survey (2000-2002). J Women's Health 2004;13:975-85.

14. Ettinger B, Grady D, Tosteson AN, Pressman A, Macer JL. Effect of the Women's Health Initiative on women's decisions to discontinue postmenopausal hormone therapy. Obstet Gynecol 2003;102: 1225-32.

15. Haas JS, Kaplan CP, Gerstenberger EP, Kerlikowske K. Changes in the use of postmenopausal hormone therapy after the publication of clinical trial results. Ann Intern Med 2004;140:184-8.

16. Kliger B. Black cohosh. Am Fam Physician 2003;68: $114-6$.

17. Kronenberg F, Fugh-Berman A. Complementary and alternative medicine for menopausal symptoms: a review of randomized, controlled trials. Ann Intern Med 2002;137:805-13.

18. Freedman RR, Woodward S. Behavioral treatment of menopausal hot flashes: evaluation by ambulatory monitoring. Am J Obstet Gynecol 1992;167:436-9.

19. Irvin JH, Domar AD, Clark C, Zuttermeister PC, Friedman R. The effects of relaxation response train- 
ing on menopausal symptoms. J Psychosom Obstet Gynaecol 1996;17:202-7.

20. Bastian LA, Breslau ES, Davis WW, Moser RP. Hormone therapy for menopausal symptoms: tracking the translation of the Women's Health Initiative findings. JCOM 2005;12:140-6.

21. NIH State-of-the-Science Panel. National Institutes of Health State-of-the-Science Conference Statement: management of menopause-related symptoms. Ann Intern Med 2005;142:1003-13.

22. U.S. Preventive Services Task Force. Chemoprevention for hormone replacement therapy. Release date: 2002. Available from: http://www.ahcpr.gov/clinic/ uspstf/uspspmho.htm 